\title{
Globalização e cosmopolitismo
}

Pedro Paulo Corôa ${ }^{1}$

Em uma época marcada pela consciência da crise em que se encontra o marxismo, temos por objetivo mostrar, com o auxílio do Manifesto do Partido Comunista ${ }^{2}$, a surpreendente atualidade do pensamento de Karl Marx. Para nós, a resistência da reflexão de Marx, típica dos pensadores que nós chamamos de clássicos, não se deve às estratégias adotadas para a realização de suas idéias, nem mesmo às vias que ele próprio propôs. Acreditamos que a sua contribuição mais consistente à economia e à política é de natureza teórica, e está ligada à profunda compreensão que o seu conceito de Weltmarkt, mercado mundial, deu-lhe para o diagnóstico da função histórica da burguesia e do proletariado na unificação do mundo humano. Nós compreendemos que as referências pelas quais, hoje em dia, definimos o que se convencionou chamar de processo de globalização, estreitamente atrelado à imagem de um mundo mercadologicamente representado, esse fenômeno aparentemente recente, está já posto no texto do Manifesto como produto natural da sociedade capitalista. À integração do mundo, ou melhor, do homem, tradicionalmente representada como unidade política, e que mesmo a religião antevia enquanto uma unidade espiritual, é dada, graças a Marx, uma base material, pois o mercado mundial é a pré-configuração da cosmopolitização, ou seja, de uma unidade política realmente sustentável.

$--\cdots+-$

1 Professor do Departamento de Filosofia UFPA.

2 Karl Marxe Friedrich Engels. Manifest der Kommunistischen Partei [Manifesto do Partido Comunista]. Stuttgart: Philipp Reclam, 1898.

120 Globalização e cosmopolitismo 
O Manifesto do Partido Comunista foi, para Marx e Engels, a oportunidade de organizar de uma forma sintética suas convicções acerca da necessidade de superar as antigas fórmulas meramente abstratas de tratamento dos temas sociais e políticos, cujo espaço de elaboração havia sido, até então, o espaço da filosofia tradicional. Por isso, ambos foram incumbidos de redigir um programa para a Liga dos Comunistas que contivesse, unidas, concepções ao mesmo tempo teóricas e práticas a serem adotadas pelo partido.

Essa unidade entre pensamento e prática revolucionária é entendida pelos autores do Manifesto como a sua maior virtude. Virtude, por sinal, que não será afetada em nada pelos constantes rearranjos e modificações das condições históricas nas quais somos obrigados a interpretar o seu significado e importância na trajetória do pensamento político moderno. Até porque a atenção às circunstâncias sucessivamente novas em que se dão os embates políticos é um problema que está, não só previsto, como incorporado às concepções da Filosofia da História marxiana.

O núcleo dessa Filosofia da História é resumido por Engels no Prefácio de 1883. Segundo ele, o pensamento essencial contido no Manifesto é que "a produção econômica e estrutura social que dela decorre constituem em cada época histórica a base da história política e intelectual dessa época"3; que os sucessivos períodos da história da humanidade correspondem a estágios de nossa evolução social nos quais a dinâmica é determinada por antagonismos entre classes. E, por fim, que esse processo atingiu, na sociedade moderna, um estágio em que as lutas contra a dominação classista, ou seja, o conflito de interesses entre a burguesia e o proletariado, só pode chegar a uma resolução na condição de estender seus resultados e possíveis conquistas à sociedade inteira, encerrando de uma vez por todas a opressão e, portanto, a própria luta de classes.

Gostaríamos de mostrar, tomando por base a tradição filosófica criticada nas teses sobre Feuerbach e na Ideologia alema $\tilde{a}^{4}$, que embora sobre um fundamento novo, de caráter essencialmente material devido ao eixo econômico com que ela se reelabora, pelo menos em seu esquema geral, essa Filosofia da história não é nova. É indiscutível que, nos termos de sua formulação, a concepção de história dialético-material é, como escreve Engels, um pensamento fundamental que pertence única e exclusiva-

$-\cdots-\cdots$

30 . cit., p. 5.

4 Karl Marx e Friedrich Engels, A ideologia alemã, São Paulo, Editora Moraes, 1984, $1^{0}$ capítulo.

cadernos cemarx, $\mathrm{n}^{0} 2-2005 \mid \mathbf{1 2} 1$ 
mente a Marx. Só que o desfecho que ela nos indica, de uma forma sem dúvida prospectiva, é uma solução que nos dá a oportunidade de recuperar, em parte, as contribuições do idealismo alemão para a construção do pensamento político moderno.

Gostaríamos de tratar isso, principalmente, por meio de dois conceitos fundamentais da filosofia da história de Marx: o de antagonismo social, como dinamizador da evolução social e política da humanidade, e a unidade final dessa humanidade, por meio de uma organização política que só pode ser a verdadeira expressão da liberdade do homem se tiver um alcance mundial. O que quer dizer: só podemos conceber, quer por meio de uma doutrina positiva (isto é, objetiva), quer especulativamente, uma solução política considerada definitiva para os problemas relativos à desigualdade e opressão dos homens, rompendo com todos os limites particulares dentro dos quais se exerce o direito à cidadania. Isso não pode ocorrer no plano dos Estados tomados individualmente, e sim no plano internacional, em um mundo cosmopolita.

Nós não pretendemos fazer com que pareçam confundir-se idealismo alemão e materialismo histórico. Bastaria lembrar o texto de a A ideologia alemã, que destaca o marco diferenciador do pensamento comunista. O que há entre esse pensamento e, diz Marx, sua antiga - dele e de Engels - "consciência filosófica" é o seguinte: "o comunismo não é para nós um estado de coisas que deva ser estabelecido, nem um ideal pelo qual a realidade deva se regular. Chamamos de comunismo o movimento real que supera o estado atual de coisas" . Pode-se dizer que o problema que Marx se coloca é o da realização dos ideais de humanidade que a Filosofia concebia, porém mantinha aprisionada no plano do pensamento puro.

Tendo bem claro essas diferenças, cremos que a leitura de um texto como Idéia de uma história universal de um ponto de vista cosmopolita, escrito pelo fundador do idealismo alemão, Immanuel Kant - a quem, aliás, Marx faz agressivas referências no Manifesto - há de causar verdadeiro espanto. Esse espanto decorre do realismo com que sua "filosofia da práxis", apesar do fundamento metafísico que tem, trata das condições de possibilidade de formulação de uma história racional da humanidade.

O propósito da filosofia da história kantiana é tentar encontrar um fio condutor para a identificação de uma certa regularidade no curso da história humana ${ }^{6}$, de modo a nos permitir fazer, contra a tradição do pensamento histórico de sua época,

$-----$

5 Marx e Engels, A ideologia alemã, op. cit., p. 5.

6 Immanuel Kant. Idéia de uma história universal de um ponto de vista cosmopolita. São Paulo, Brasiliense, 1986, p. 9.

122 Globalização e cosmopolitismo 
um esboço de unidade interpretativa para a sucessão aparentemente arbitrária das ações humanas no tempo.

Para Kant, o que se apresenta a nós como confuso e irregular nas ações dos sujeitos tomados isoladamente pode ser reconhecido como um desenvolvimento contínuo e progressivo das nossas disposições originais, se deixarmos de lado o indivíduo e pensarmos no conjunto da espécie. Afinal, não faz nenhum sentido tratar a história universal do ponto de vista do indivíduo. Ainda que esse desenvolvimento não se dê segundo um plano consciente, é inegável, pensa Kant, que há uma modificação gradual do nosso modo de existência social, portanto, coletiva, que pode ser traduzida na forma de uma evolução que não se deixa perceber no indivíduo e sim na espécie.

Na reflexão sobre a história no Idealismo Alemão, como em Marx, o "x" da questão é saber como, diante de um quadro de conflitos e dificuldades que nos ameaçam constantemente, nossa ação individual acaba por ter um resultado que nos ultrapassa, como se houvesse leis, independentes de nossas vontades, análogas às leis da natureza, que agissem sobre nós de modo a dar-nos uma coesão enquanto espécie, que, os indivíduos, eles mesmos, não buscam por si sós e deliberadamente. É assim que, de modo geral, por meio das diferentes filosofias da história, principalmente, desde Agostinho, se tenta desvendar em que direção nossa luta diária pela sobrevivência e aperfeiçoamento individual nos conduz - somados todos os nossos feitos, acertos e defeitos. $O$ que está em jogo é a busca de referências que nos permitam vislumbrar se há um sentido, uma lógica intrínseca aos acontecimentos que compõem nossa história.

Os termos dessa questão são formulados com base na interpretação da história da humanidade em sua totalidade, e o chamado "desenvolvimento" do homem enquanto espécie é entendido como um processo orgânico de maturação das condições objetivas, quero dizer, políticas, necessárias para uma existência plena e acabada, dentro da qual, efetivamente, as potencialidades individuais possam se manifestar livremente.

Kant está convencido de que o desenvolvimento das habilidades da espécie humana no domínio da cultura só pode ocorrer por meio de uma tensão entre os homens. Devido a isso, diz Kant, já na Crítica do Juízo, que a maior parte de nós "é mantida pela minoria em um estado de opressão, de trabalho amargo e gozo escasso, ainda que a cultura das classes superiores se estenda pouco a pouco a esta inferior"

\footnotetext{
$--\cdots+-$
}

7 Immanuel Kant, Kritik der Urteilskraft [Crítica da Faculdade de Julgar]. Hamburg, Felix Meiner, 1974, p. 83.

cadernos cemarx, $n^{0} 2-2005 \mid 123$ 
Para Kant isso só se resolve em um acordo entre os homens que permita opor uns aos outros de uma forma universalmente regulada, na sociedade civil, graças ao uso de uma força legal que contenha os abusos da liberdade que estão em constante oposição e conflito. Assim sendo, mantém-se aquela condição antagônica que está no fundamento do nosso desenvolvimento cultural e social, ao mesmo tempo em que a submetemos a um controle civil. E como esse controle do abuso das liberdades diz respeito a toda espécie humana, a única garantia de que o mesmo seja efetivamente respeitado, é a organização da espécie num todo cosmopolita. De todo modo, a idéia que orienta essa filosofia da história é a de que, os antagonismos sociais, a "insociável sociabilidade humana", ${ }^{8}$ é o que prepara, quando não funda, as condições graças às quais deve se instaurar uma legalidade com liberdade, e com isso a unidade sistemática de todo os homens enquanto cidadãos do mundo, numa sociedade cosmopolita.

A sociedade burguesa moderna, diz o Manifesto, é até agora o estágio mais avançado do desenvolvimento da historia humana. Mas não porque tenha reduzido os antagonismos de classe que marcam as fases anteriores. Muito pelo contrário, é nela em que tais conflitos assumiram sua expressão mais aguda ao por fim às nossas ilusões de liberdade com a exploração mais evidente e direta da força de trabalho dos homens. Ela reduziu de uma vez por todas os pólos do antagonismo, pondo de um lado os patrões e fazendo de nós assalariados. Ela criou as condições para a síntese completa da força trabalhadora, dando assim os fundamentos para sua unidade.

A descrição do cenário histórico no qual se dá o desenvolvimento da burguesia no Manifesto é o da mundialização das relações de produção e do mercado que lhe é correlato. É exatamente a expansão das redes de comércio por todo o globo terrestre e o incremento da indústria com vistas a satisfação das expectativas de um mercado cada vez mais amplo que, na análise de Marx, consolidou de vez o domínio burguês nas relações de produção, aniquilando para sempre a antiga sociedade feudal.

Conclusão: os problemas intrínsecos às relações entre a burguesia e o proletariado, na medida em que têm que acompanhar essa internacionalização, levam a uma universalização dos conflitos de interesse, o que parece impor uma solução também mundial, portanto única, para os mesmos, atingindo com isso todos os cantos do planeta.

$-\cdots-\cdots$

8 Immanule Kant, Idéia de uma história universal, op. cit., p13.

124 Globalização e cosmopolitismo 
É esse o sentido do lema posto ao final do Manifesto: "Proletários de todos os países, uni-vos!", que expressa muito bem o que, na concepção marxiana, constitui-se numa necessidade histórica produzida pelo alastramento da atividade capitalista: a internacionalização do movimento de reação operária, dando a ele uma unidade necessária tendo em vista a completa identificação entre seus interesses. É esse, aliás, o objetivo da "Liga dos Comunistas", entendida por seus membros como uma organização partidária internacional destinada a defender os interesses da classe operária em todo planeta.

A condição da consolidação do sistema capitalista é a integração do mundo, descrita, já no Manifesto, como fenômeno mediado por exigências derivadas da lógica do mercado. A burguesia industrial promove com isso, talvez, o primeiro fenômeno global. E é provavelmente isso que o texto do Manifesto quer dizer ao afirmar que a sociedade burguesa criou novas formas de opressão, mas, por sua vez, novas formas de luta cuja conseqüência deve ser, devido à polarização dos conflitos, não simplesmente o deslocamento para um estágio a mais na história social da humanidade, e sim a resolução completa de seus conflitos pela supressão da propriedade privada.

E como a cada etapa da evolução da humanidade corresponde uma forma determinada de dominação política, a revolução das relações de produção pelo proletariado deve poder redundar, também, na conquista de sua soberania política, assim como o estabelecimento do mercado mundial significou para a burguesia a conquista do poder no Estado representativo moderno.

Quando o Manifesto nos fala que a criação do mercado mundial pela burguesia, imprime um caráter cosmopolita ${ }^{10}$ à produção e ao consumo em todos os países, isso significa que o conceito de mundialização (globalização) da economia é, dentro da filosofia da história marxiana e da análise política que dela decorre, a base de redefinição das concepções tradicionais que aponta como única garantia de libertação do homem a definição de metas que atinjam a espécie como um todo.

Sua filosofia da história e a prospecção (idéia de uma comunidade socialista) que ela orienta, justifica, a partir da idéia de mundialização do mercado capitalista um

$--\cdots--$

9 Conferir o primeiro prefácio à edição alemã, de 1872, assinado por Marx e Engels.

100 texto do Manifesto é bem claro: A burguesia, através da exploração do mercado mundial [Weltmarkts], deu uma forma cosmopolita à produção e ao consumo de todos os países. op. cit., p. 23.

cadernos cemarx, $\mathrm{n}^{0} 2-2005 \quad \mathbf{1 2 5}$ 
conceito de cosmopolitismo que só tem sentido se compreendermos bem a vinculação e a necessidade da inter-relação entre revolução material e revolução política na doutrina de Marx.

Cabe perguntar se o fenômeno da globalização, tal como o encontramos hoje permite algum diagnóstico que alimente em nós a mesma esperança de resolver de forma favorável a exclusão observada no estágio atual das relações de produção. E se podemos ainda esperar a sobrevivência da idéia de cosmopolitismo como construção de uma política mundial dirigida para o homem enquanto espécie.

$1 \overline{26}$ Globalização e cosmopolitismo 